
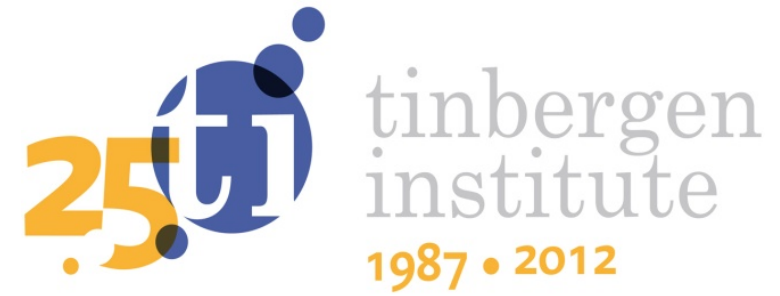

\title{
The Creative Urban Diaspora Economy: A Disparity Analysis among Migrant Entrepreneurs
}

\author{
Karima Kourtit ${ }^{1}$ \\ Peter Nijkamp ${ }^{1,2}$ \\ Daniel Arribas-Be/3
}

1 Faculty of Economics and Business Administration, VU University Amsterdam;

2 Tinbergen Institute;

3 Arizona State University, Tempe, Arizona, United States of America. 
Tinbergen Institute is the graduate school and research institute in economics of Erasmus University Rotterdam, the University of Amsterdam and VU University Amsterdam.

More TI discussion papers can be downloaded at http://www.tinbergen.nl

Tinbergen Institute has two locations:

Tinbergen Institute Amsterdam

Gustav Mahlerplein 117

1082 MS Amsterdam

The Netherlands

Tel.: +31(0)205251600

Tinbergen Institute Rotterdam

Burg. Oudlaan 50

3062 PA Rotterdam

The Netherlands

Tel.: +31(0)10 4088900

Fax: $+31(0) 104089031$

Duisenberg school of finance is a collaboration of the Dutch financial sector and universities, with the ambition to support innovative research and offer top quality academic education in core areas of finance.

DSF research papers can be downloaded at: http://www.dsf.nl/

Duisenberg school of finance

Gustav Mahlerplein 117

1082 MS Amsterdam

The Netherlands

Tel.: +31(0)20 5258579 


\title{
THE CREATIVE URBAN DIASPORA ECONOMY: A DISPARITY ANALYSIS AMONG MIGRANT ENTREPRENEURS
}

\author{
Karima Kourtit \\ VU University \\ Dept. of Spatial Economics \\ Amsterdam \\ k.kourtit@vu.nl
}

\author{
Peter Nijkamp* \\ VU University \\ Dept. of Spatial Economics \\ Amsterdam \\ p.nijkamp@vu.nl
}

\author{
Daniel Arribas-Bel \\ Arizona State University \\ GeoDa Center for Geospatial \\ Analysis and Computation \\ Tempe, Arizona \\ darribas@asu.edu
}

Pn456kkda

\begin{abstract}
This paper highlights the 'magic of diasporas' - as a source of progress in a globalizing world with special attention for migrant (or ethnic) entrepreneurship. The present study aims to identify and examine the critical critical success factors of migrant enterprises and their socioeconomic implications in modern cities. We will assess the business performance of migrant entrepreneurs by employing a new analytical instrument, coined Super-Efficient Data Envelopment Analysis (Super-DEA). Next, we will offer a multidimensional visualization of the relative differences in the performance of migrant entrepreneurs by introducing a recently developed technique from the cognitive sciences, coined Self-Organizing Maps (SOMs). This analytical apparatus will be tested on the basis of a sample of Moroccan entrepreneurs in four Dutch cities, namely Amsterdam, Rotterdam, The Hague and Utrecht. The study will be concluded with some strategic conclusions.
\end{abstract}

* Tinbergen Institute, The Netherlands.

\section{Key words:}

migrant entrepreneurship, diaspora economy, ethnic diversity, foreign migrants, economic performance, social capital, immigrant networks, social networks, Super-Efficient Data Envelopment Analysis, Self-Organizing Maps, SWOT analysis, migration impact assessment

JEL: L26, O15 


\section{The Diaspora Economy}

A recent article in The Economist (November 19, 2011) highlighted the 'magic of diasporas' by arguing that foreign migrants make a significant contribution to a nations' economic growth. In particular, immigrant networks are a source of progress in a globalizing world. Many foreign migrants are not individual opportunity seekers, but exhibit a herd behaviour in which social bonding and mutual support systems among members of the same ethnic or socio-economic group are crucial success conditions. Such diaspora networks based on kinship, language, culture or geography appear to create the basis for new and flexible forms of economic activity, in which social capital and trust play an important role (see Kloosterman and Rath 2001). Clearly, there are additional factors that also help to create the foundation for a successful economic operation by migrants in host countries, in particular, knowledge, involvement in local cultures, and accessibility to broader communication and social exchange networks (see also Fukuyama 1996, and Putnam 2000).

There has been an upsurge of - often unjustified or politically motivated - views on the negative socio-economic impacts of foreign migrants. As extensively demonstrated by Nijkamp and Poot (2012), many of such assertions are based on wrong prejudices or false premises; the actual contribution of migrants to local or national economies range from modest to significant positive impacts. Clearly, there are cases of crowding-out effects and negative externalities, but in most situations such phenomena are offset by other positive welfare consequences for local or national economies at large. And with an increasing dominance of skilled migration, the positive impacts of foreign migrants for host counties will likely rise even more.

The integral and systematic assessment of local, regional or national effects of the presence and of the economic participation of foreign migrants is called 'migration impact assessment' (MIA) and has led to a new strand of applied quantitative impact studies on foreign migration. A overview and illustrations can be found in a recent study of Nijkamp et al. (2012).

Admittedly, migration is a social-geographic phenomenon of all times and places, and hence not unique for our era. But the scale and international coverage of this phenomenon make it new in our age, with more than three per cent of the world's population living outside the country of birth. In a way, migration is a sign of the increasing globalization of our societies which runs parallel to the rising flow of goods and services, (sub-)cultures, information, expertise, knowledge or technology across traditional boundaries. Unravelling the multidimensional economic aspects and effects of foreign migrants is fraught with many difficulties, but MIA can be instrumental in mapping out and assessing the most prominent impacts. This calls for a systematization and operational typology of these impacts. In a recent study by Christensen et al. (2011) four principal, quantifiable categories were distinguished:

- contributions to federal, state, and local revenues in the form of income, property, sales, and other taxes and fees;

- $\quad$ contributions to gross domestic product (GDP) in the form of consumer spending;

- contributions to economic output and national income based on the immigrants' influence on labour productivity;

- $\quad$ contributions to job creation and new business formation. 
A review of experiences and findings from a broad MIA can be found in a recent study by Kourtit and Nijkamp (2011a). The authors have summarized various findings by designing a framework for a migration SWOT (strength-weakness opportunities-threats) analysis based on five distinct domains of prominent socio-economic importance. The results from each SWOT analysis were then used as an input for compiling strategic choices and possible policies.

In the present study, we will focus our attention in particular on an issue of increasing importance in western cities, viz. migrant or ethnic entrepreneurship. Our aim is to identify the critical success factors of migration business and their socio-economic implications. We will measure the business performance of migrant entrepreneurs by employing an appropriate analytical instrument, coined Super-Efficient Data Envelopment Analysis (Super-DEA). Next, we will offer a new visualization of the relative differences in the performance of migrant entrepreneurs by introducing a recently developed technique from the cognitive neuro (or learning) sciences, namely Self-Organizing Maps (SOMs). This analytical apparatus will be tested on the basis of a sample of Moroccan entrepreneurs in the four largest Dutch cities namely Amsterdam, Rotterdam, The Hague and Utrecht, followed by an interpretation of our findings. The study will be concluded with some strategic conclusions.

\section{Migrant Entrepreneurship}

Migrant entrepreneurship - sometimes called ethnic entrepreneurship or minority entrepreneurship - has become a vehicle for many foreign migrants to reach the 'heaven's door' (Borjas 1999), either in a voluntary way (as an opportunity seeker) or in a forced way ('the stranger is the trader'). In many countries, foreign-born immigrants have led to the birth of many new firms, often in the lower segments of the business market such as repair services or catering (see the 'market penetration' concept in the Ansoff 1957 Model), where newcomers increase their market share in a competitive business market with low-cost products or services. Sometimes these business firms move to a higher segments, e.g., engineering firms, marketing and consultancy firms (see the 'diversification' concept in the Ansoff 1957 Model), where they develop and provide a new product or service for a completely new market ('break-out strategies'). With the advent of the knowledge-driven society, we see also the emergence of high-tech and advanced business firms in migrant segments of society based on innovativeness and intellectual property. Figure 1 shows clearly a drastic transformation and re-positioning of ethnic entrepreneurship, in particular the second and third generation, towards innovative or creative industries in urban agglomerations ('breaking-out approach').

Figure 1 shows a systematic strategic framework of migrant entrepreneurship that is helpful for mapping out new business growth strategies and opportunities of migrant firms, derived from the Ansoff 1957 Model). This model is based on two dimensions, namely products \& services and markets, for which four growth strategies can be developed, viz. market penetration, market development, new product \& service development, and diversification.

In general, ethnic businesses have the innovative drive to grow by employing business actions for determining the best course of action, where growth is their priority. Figure 1 shows 
that new trends in ethnic entrepreneurship and in innovative growth strategies tend to show a rise in second-generation migrant entrepreneurs in the creative sector towards an external market orientation ('break-out strategies'; see also Engelen 2001), instead of focusing on the traditional sectors, in which the first generation is operating. They aim to expand their market domain by means of diversification through 'break-out strategies' by offering high quality and innovative products and services for a broader group of clients and markets outside their own co-ethnic clientele.

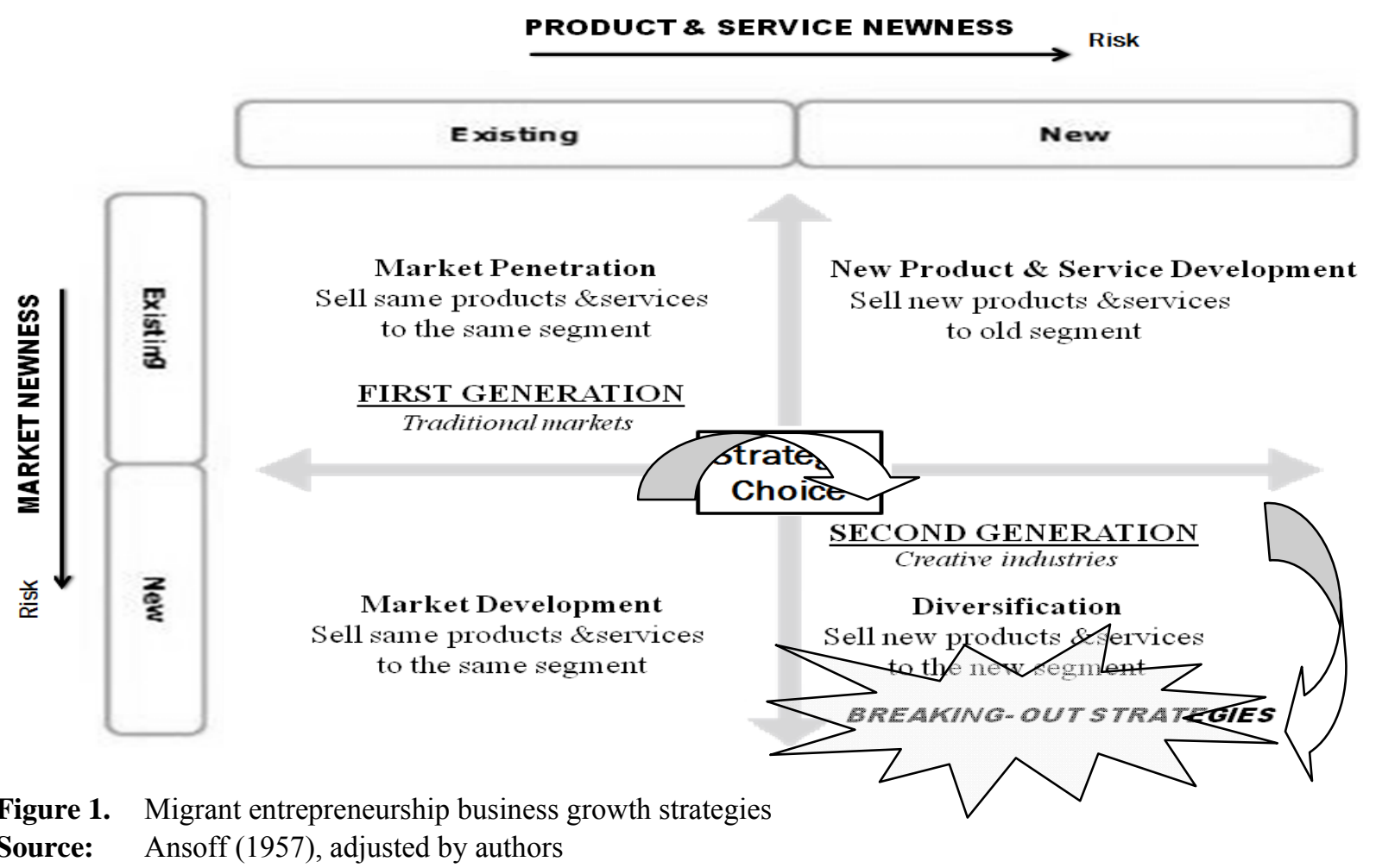

Nowadays, the first-generation entrepreneurs tend to look also increasingly for new opportunities by providing new products and services in order to increase their sales and profits, though in an existing business market (from market penetration towards new product \& service development). Thus, they often try to develop and provide other new products to their regular (co-ethnic) customers or to a market which they have already entered. On the other hand, the second generation uses increasingly new types of strategic approaches for detecting innovative growth strategies. Their business strategies are based on conglomerate diversification and rather risky type of strategies, because they enter new markets with new products or services.

It is noteworthy, that - most of these firms have started in a rather informal and flexible way, but - especially in the stage of second-generation migrants - they have been upscaled to modern R\&D-oriented firms ('break-out approach') (Kourtit and Nijkamp 2011b). Recent research (Sahin et al. 2010, 2012; Kourtit and Nijkamp 2012) has shown that the second generation of ethnic entrepreneurs tends to be well-educated, and better integrated in the host 
community, where this community is mostly also the country of birth of this new generation. An extensive review of the literature and a series of applied studies can be found in Sahin (2012).

An important conclusion from recent research is that the migrants' talents, capacities and resources matter - and their less so ethnicity - in achieving business performance and success. Given this new perspective on a variety of motives and background conditions of migrant entrepreneurs, it seems plausible to hypothesize that their economic performance will also show quite a diversity, not only among different ethnic groups, but also across age or education. This will be further tested in the present study.

It should be noted at the outset that migrant business does not demonstrate a uniform socioeconomic spectrum; it covers a wide range of economic activities ranging from traditional to sophisticated, from low-skilled to high-skilled market segments. High-skilled migration, in particular, tends to create a well-educated diaspora which facilitates trade by helping to enforce contracts, acts as intermediaries or brokers, and expands international cooperation (World Bank 2006, Nijkamp et al. 2012). In the context of an ageing population and the need for proper skills and talents, migrants may make an important economic contribution to the host region. Since many migrants move from poor to rich countries, one may argue that the globalisation process prompts spatial mobility and accessibility to places with a different socio-economic profile (Poot et al. 2008). At the beginning, migrant enterprises may be oriented towards traditional ethnic products from the country of origin, but - as mentioned - they are also increasingly found in advanced producer services in a modern economy.

The above described new orientation on non-traditional sectors with a combination of attractive personal characteristics, skills and experience may produce a high economic performance and success level for the second-generation migrant entrepreneurs. This new orientation may also help them to escape from the 'social trap', or from ethnic or migrant enclaves causing less incentives for a full fledged social and labour force participation. This new attitude enhances also social cohesion, solidarity and trust in the crowded melting pot of modern cities. Such break-out strategies are increasingly supported by formal networks or organisations or institutional back-up systems. Moreover, this new external orientation may also help them to expand their market towards a higher volume by engaging in commercial contacts with indigenous entrepreneurs and other ethnic groups, which may positively contribute to the local or regional business climate and urban vitality. However, this external orientation does not mean that they will stop benefiting from their own ethnic group ('enclave economy'). Thus, migrant groups who produce a strong entrepreneurial climate can be of great economic significance for the migrant community itself, as well as for the entire community, e.g. through job and opportunity creation.

The increasing variety of migrants may prompt a great cultural diversity, mainly in urban agglomerations (e.g., in terms of local identity, an open and attractive urban 'milieu' or atmosphere, use of tacit knowledge, local embeddedness of new business initiatives, and access to social and financial capital and networks). It can also significantly contribute to the local or regional economy by increasing the economic and cultural diversity of a city and reducing unemployment among immigrants. As a consequence, many cities in the Western world gradually become a multicultural melting pot: a society with people of different cultures, races 
and religions (Jacobs, 1961) and a magnet to deliver new ideas for the creative industries and economic growth. Thus, they mirror an amazing spectrum of activity patterns that are to a large extent co-determined by the specificities in terms of culture, language, attitude or behaviour related to the country of origin. They exhibit a new socio-economic potential that may further enhance trade, with its intriguing mix of competitiveness and cooperative behaviour, which represents a new challenge and provides opportunities for many cities in host countries. International studies of various cities show that cultural diversity leads to favourable socioeconomic conditions where there are complementary labour opportunities or niche-markets. Managing cultural diversity - with a focus on the optimisation of potential socio-economic benefits of cities - requires the utmost in strategic courage and governance ability (Kourtit and Nijkamp 2012).

Diversity has in general a positive effect on creativity, innovation and performance at different scales from company or organization to city, region or country. The reason is that being linked to creative activities is a major source of competitiveness for multicultural cities, as it not only stimulates creative ideas and facilitates creative activities, but also encourages cities to boost their international profile, e.g. by attracting investment and a well-educated, creative workforce. Therefore, cultural diversity tends to contribute to the improvement of the creative capacities of cities and regions (see Florida 2002, Landry 2000, Scott 2006). While Jane Jacobs (1961) was still talking about the urban 'melting pot' as the source of creative entrepreneurship, nowadays we speak of a 'mosaic '(see Gang et al. 2011) as a culturally distinct but economically integrated urban migrant constellation.

Cultural diversity may creative diverse economic activity patterns among migrants, but an important question is whether such economic diversity can also be observed among business owners of the same ethnic or cultural background. In other words, it is an intriguing question whether enterprises with a given cultural or geographic origin have a similar business performance. The answer to this question calls for a conceptual and operational business performance model which comprises both individual-specific determinants (e.g. skills, age) and general moderator variables (e.g. geographic location). This set of micro and meso input variables then determines the output (or performance indicators) of the firm concerned. In other words, our conceptual model can be presented as follows (see Figure 2):

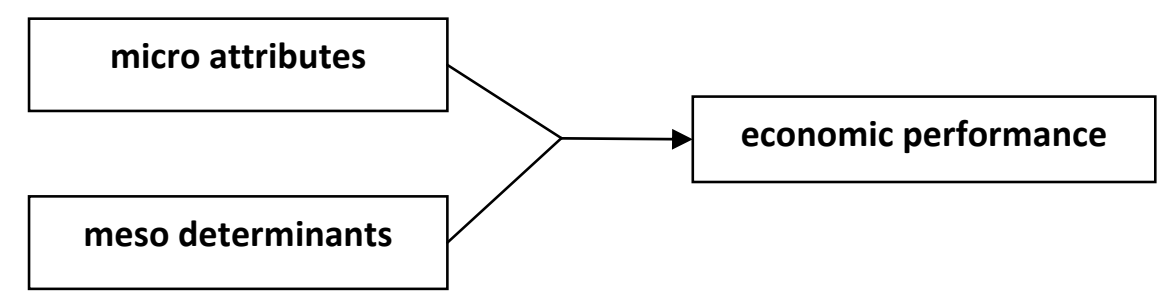

Figure 2. A simple performance scheme for business firms

The input variables call for a combined micro-meso data set on the attributes and moderator variables of individual firms, while the analysis of their business performance has to be based on individual firm achievement information. Our database will be based on extensive 
field interviews with a sample of Moroccan entrepreneurs in the four largest cities in the Netherlands (see Section 3). Next, the economic analysis of the firms' performance will use a recently developed and tested method for comparative business achievement viz. a SuperEfficient Data Envelopment Analysis (Super-DEA) (see Section 4). In the subsequent section, the statistical analysis of the disparities among these migrant firms will be presented, while we use a relatively new method for socio-economic data and mapping analysis, called a SelfOrganizing Map (SOM) (see for an introduction Section 5). Finally, in Section 6 the empirical

results of the Super-DEA experiment and of the SOM experiment will be combined and interpreted, while Section 7 will offer some concluding remarks.

\section{Description of Database}

This section will describe the details of our database and the methodology employed. Our study aims to investigate the critical success factors (CSFs) behind the business performance of the new-generation migrant entrepreneurs who are active in creative or innovative sectors, and to assess their socio-economic implications. Our case study will address the economic performance of Moroccan entrepreneurs in the Netherlands. Therefore, in our research we will present the results of an investigation on one of the three largest ethnic groups in the Netherlands, which has shown the sharpest rise in absolute numbers of non-Western entrepreneurs and a relatively high birth rate of new firms. These are the higher-educated young Moroccan entrepreneurs operating in the ICT, consultancy, marketing, media, financial, and real estate sectors, mostly concentrated in the four largest Dutch cities, namely Amsterdam, Rotterdam, The Hague and Utrecht. These cities have also a large share of many ethnic groups present in the Netherlands.

The important research question is now whether these ethnic firms, with a similar cultural or geographic origin, have the same business performance, in particular financial as well as nonfinancial achievements, even when they are using a relatively small amount of inputs. All these factors are at the core of the simple conceptual model (see Figure 2) developed in this paper, while their importance and business impact will be assessed on the basis of an extensive data set on theseentrepreneurs. Thus, our empirical approach is based on unique data gathered from a structured in-depth field survey of a selected set (24) of rather representative Moroccan entrepreneurs in the business-related professional service sectors with a relatively high educational level and skills. They are different from the traditional ethnic niche in terms of their products, services and communication channels used. Clearly, the sample is relatively small, but in this emerging new market it turned out to be extremely difficult to find a large set of secondgeneration entrepreneurs who were willing to participate in our interview.

To answer to our research question, our simple conceptual model (Figure 1) has been adjusted accordingly, and thus all main input and output factors have been included in the model, which comprises both individual-specific determinants (e.g., skills, age) and general moderator variables (e.g. geographic location). This set of micro- and meso-input variables serves as independent explanatory factors that are supposed to determine the overall outputs (or performance indicators) of the firms concerned. 
In order to avoid the collection and use of unstructured micro- and meso-input data, the long list of indicators from the survey questionnaire was systematized and summarized by means of a clustered presentation in 5 input groups (see Table 1), which contains the relevant main indicators. These input groups are: Human Capital (HC), Social Capital (SC), Creative Capital \& Knowledge Capital (CC\&KC), Financial Capital (FC) and Entrepreneurship Capital (EC). Similarly, the outputs of these individual firms were also clustered according to two main characteristic groups, viz. Financial business performance (FBP1\&2), and Non-financial business performance (NF-BP3). Finally, the precise geographical coordinates of these firms were, of course, known. And therefore, it was possible to assign the location of each individual firm in our study. Table 1 offers a compact, systematic picture of the general main categories of the micro- and meso-indicators used in this research.

These individual firm data are related to both output and input performance characteristics, as well as to motivational and driving forces that are decisive for turning the firm into a highperformance firm, a so-called 'business champion'. As a prior broad literature search did not create a solid basis for a useful, validated questionnaire to obtain verified and systematically structured individual information from the firms on their critical performance success conditions and indicators that reflect innovations in the relevant sectors, a self-composed 'statement questionnaire' was used (related to all the above main categories). The participating Moroccan entrepreneurs were selected on the basis of two dominant criteria, namely whether they operate in the advanced and/or creative industries, and have a Moroccan background. The performance statements in the questionnaire were next identified from the broad literature available (indicators were converted into statements and presented to the interviewees) and were then reformulated so that the interviewees had to give a rating on a 5-point Likert scale, varying from 5 (the highest score per answer) to 1 (the lowest). The average sum of the scores for each of the indicators was used for further statistical analyses.

This conceptual input and output information framework was used to identify the critical success factors of migration business and their socio-economic implications. In order to measure the business performance and to judge in an appropriate way the comparative achievement of these ethnic firms, a new analytical instrument, coined Super-Efficient Data Envelopment Analysis (Super-DEA) was employed (see Section 4). The aim of a general DEA is to obtain by way of a benchmark analysis - comparative insight into the relative efficiency of a decision unit as compared to other decision units. Next, in Section 5, we will introduce a new analytical visualization technique that is able to map out the relative differences in the performance drivers and the business performance of migrant entrepreneurs in the Dutch cities concerned. This method, which is able to identify and explain their positions in virtual topological space, is based on an increasingly popular approach from neuro-learning sciences, namely Self-Organizing Maps (SOMs). This analytical apparatus will be tested on the basis of our sample of Moroccan entrepreneurs in four Dutch cities in Section 6. 
Table 1. List of input and output indicators of Moroccan entrepreneurs

\begin{tabular}{|c|c|c|c|}
\hline MAIN CATEGORIES & INDICATOR GROUP & NR & INDICATORS \\
\hline \multirow{2}{*}{ OUTPUTS } & Financial business performance (FBP1\&2) & $\begin{array}{l}1 \\
2\end{array}$ & $\begin{array}{l}\text { Sales } \\
\text { Profit }\end{array}$ \\
\hline & Non-financial business performance (NF-BP3) & $\begin{array}{l}3 \\
4\end{array}$ & $\begin{array}{l}\text { Higher orientation } \\
\text { Higher quality }\end{array}$ \\
\hline \multirow[t]{5}{*}{ INPUTS } & Human Capital (HC) & $\begin{array}{c}5 \\
6 \\
7 \\
8 \\
9 \\
10 \\
11\end{array}$ & $\begin{array}{l}\text { Age } \\
\text { Education level } \\
\text { Education place } \\
\text { Educational level } \\
\text { Language ability (e.g. Dutch, English, French) } \\
\text { Country birth } \\
\text { Arrival years in the Netherlands } \\
\text { Reasons to start up a business }\end{array}$ \\
\hline & Social Capital (SC) & $\begin{array}{l}12 \\
13\end{array}$ & $\begin{array}{l}\text { Network participation } \\
\text { Support from social network }\end{array}$ \\
\hline & Entrepreneurship Capital (EC) & $\begin{array}{l}14 \\
15 \\
16 \\
17 \\
18 \\
19 \\
20 \\
21 \\
22 \\
23 \\
24 \\
25 \\
26 \\
27 \\
28\end{array}$ & $\begin{array}{l}\text { Starting situation firm } \\
\text { Problems startup } \\
\text { Sector choice } \\
\text { Situation sector } \\
\text { Present situation sector } \\
\text { Market competition in sector, } \\
\text { Attractive market } \\
\text { Diversity in clientele } \\
\text { Number of clientele } \\
\text { Strategic segmentation } \\
\text { Marketing strategies and efforts } \\
\text { Managerial support } \\
\text { Operational support } \\
\text { Vision and business strategies } \\
\text { Professionalization and market expansion }\end{array}$ \\
\hline & Creative Capital \& Knowledge Capital (CC\&KC) & $\begin{array}{l}29 \\
30 \\
31 \\
32 \\
33 \\
34 \\
35\end{array}$ & $\begin{array}{l}\text { Foundation year of enterprise } \\
\text { Position before start-up } \\
\text { Previous experiences } \\
\text { Business plans for start-up } \\
\text { Informal and formal information sources } \\
\text { Diversity in employees } \\
\text { Number of employees }\end{array}$ \\
\hline & Financial Capital (FC) & $\begin{array}{l}36 \\
37\end{array}$ & $\begin{array}{l}\text { Formal capital sources } \\
\text { Informal capital resources }\end{array}$ \\
\hline $\begin{array}{l}\text { GEOGRAPHIC } \\
\text { LOCATION }\end{array}$ & Four largest Dutch cities (G4) & $\begin{array}{l}38 \\
39 \\
40 \\
41\end{array}$ & $\begin{array}{l}\text { Amsterdam } \\
\text { Rotterdam } \\
\text { The Hague } \\
\text { Utrecht }\end{array}$ \\
\hline
\end{tabular}

\section{Data Envelopment Analysis (DEA): Standard Model and Super-Efficiency DEA (Super- DEA) Model}

\subsection{The standard DEA (CCR) model}

The standard Charnes et al. (1978) model (abbreviated hereafter as the CCR-input or CCRI model) for a given Decision-Making Unit $\operatorname{DMU}_{j}(j=1, \cdots, J)$ to be evaluated in any trial $o$ (where $o$ ranges over $1,2 \ldots, J$ ) may be represented as the following fractional programming $\left(F P_{o}\right)$ problem: 


$$
\begin{gathered}
\left(F P_{o}\right) \quad \max _{v, u} \theta=\frac{\sum_{s} u_{s} y_{s o}}{\sum_{m} v_{m} x_{m o}} \\
\text { s.t. } \quad \frac{\sum_{s} u_{s} y_{s j}}{\sum_{m} v_{m} x_{m j}} \leq 1(j=1, \cdots, J) \\
v_{m} \geq 0, u_{s} \geq 0,
\end{gathered}
$$

where $\theta$ represents an objective variable function (efficiency score); $x_{m j}$ is the volume of input $m$ $(m=1, \ldots, M)$ for DMU j $(j=1, \ldots, J) ; y_{s j}$ is the output $s(s=1, \ldots, S)$ of DMU j; and $v_{m}$ and $u_{s}$ are the weights given to input $m$ and output $s$, respectively. Model (1) is often called an input-oriented CCR model. This model is obviously a fractional programming model, which may be solved stepwise by first assigning an arbitrary value to the denominator in (1), and then maximizing the numerator.

By undertaking a DEA to a comparable set of DMUs, it is possible to assess the productivity (efficiency or performance) of each DMU in relation to others. Any DMU located on the production possibility frontier of the DMUs concerned may be regarded as efficient and receives a score of 1 . All other DMUs operate inefficiently and get a score lower than 1 . In this way it is possible to arrive at a deterministic rating of the performance of all DMUs. This approach has been applied many times in comparative studies on firm performance in business administration.

\subsection{The super-efficiency model}

In a standard DEA all efficient firms get an equal score of 1 . The unsatisfactory identification of efficient firms in a standard DEA model - where all efficient firms get the score 1 - has led to focused research to discriminate between efficient DMUs, in order to arrive at a ranking - or even numerical rating - of these efficient firms, without affecting the results for the non-efficiency. Anderson and Petersen (1993) have developed the super-efficiency model to arrive at a ranking of all efficient DMUs. The efficiency scores from super-efficiency model are obtained stepwise by a successive elimination of the data on the $\mathrm{DMU}_{o}$ to be evaluated from the entire solution set. If this position really matters, the firm at hand is more efficient. For the input model, this can then result in values which may be regarded - according to the $\mathrm{DMU}_{o}$ - as a state of super-efficiency. These values are then used to rank the DMUs and, consequently, efficient DMUs may then obtain an efficiency score above 1. This super-efficiency model (Super-DEA) may be suitable to find the highest performing DMU. A Super-DEA model based on a CCRinput model can be written as follows:

$$
\min _{\theta, \lambda, S^{-}, S^{+}} \theta-e s^{-}-e s^{+}
$$




$$
\begin{aligned}
& \text { s.t. } \quad \theta x_{o}=\sum_{j=1, \neq 0}^{J} \lambda_{j} x_{j}+s^{-} \\
& y_{o}=\sum_{j=1, \neq 0}^{J} \lambda_{j} y_{j}-s^{+} \\
& \lambda_{j}, s^{-}, s^{+} \geq 0
\end{aligned}
$$

where $e$ is a unit vector $(1, \ldots, 1)$.

In general, a Super-DEA model aims thus to identify the relative importance of each individual efficient firm, by designing and measuring a score for its 'degree of influence' if this efficient firm is omitted from the efficiency frontier (or production possibility set). If this elimination really matters (i.e. if the distance from this DMU to the remaining efficiency frontier is large), and thus the firm concerned has a high degree of influence and outperforms the other DMUs, it gets a high score that exceeds the critical value 1 (and is thus super-efficient). Thus, for each individual efficient firm a new distance result is obtained, which leads to a new ranking even a rating - of all original efficient firms. The Super-DEA model may thus be suitable to find - for our comparative database on ethnic entrepreneurs - the set of highest performing firms (see also Suzuki et al 2010, 2011). This method will be used in our search for the 'magic of diasporas' using statistical analyses of the disparities in performance among these migrant firms.

\section{The Self-Organizing Map (SOM)}

The Self-Organizing Map (SOM), is an algorithm that belongs to the family of computational neural networks (see for an exposition Kohonen, 2001). It is a data-reduction technique that was first developed in relation to the study of the spatial organization of brain functions and aimed to perform two main types of compression: on the one hand, it shrinks the number of input observations (quantization ); on the other hand, it compresses the number of dimensions or attributes of each observation, usually to two of them (projection ). Although it has not been widely applied in the context of social sciences until recently (see e.g., Skupin and Hagelman 2005, Spielman and Thill 2008, Yan and Thill 2009, ArribasBel et al. 2011), the SOM features a number of characteristics that make it very useful for exploration and presentation of complex relationships buried in high-dimensional socioeconomic datasets. This in turn converts it in a useful device to present information in an intuitive way to a non-technical audience, for instance, in the context of decision making support.

Most of the interest on the SOM stems from its ability to spatially represent statistical relationships. In effect, the algorithm is able to extract the meaningful information in the various dimensions of the data and collapse them usually into only two. These two dimensions may then be plotted in what is also called a SOM, a graphical device whose topological structure preserves the statistical patterns contained in the original data. This is achieved through an iterative process called training, in which the the dataset is sequentially presented to the 
SOM, which progressively learns its properties, hence the concept of self-organization. Since a detailed description of the technique is well beyond the scope of this paper, in this section we focus mainly on the intuition, describe the output of a SOM and put particular emphasis on how to interpret it.

Typically, the output of a SOM is a network of topologically connected hexagons that represent the "compressed" version of the original multi-dimensional dataset. A vector of as many dimensions as original variables is assigned to each of these hexagons and, once the SOM has undergone the training process, these vectors contain the statistical properties of the original dataset. Not only that, such properties are also distributed across the network in a way that similarity is translated into distance: closer hexagons tend to be very similar in terms of the statistical characteristics from the original dataset, while more distant ones are less alike. It is important to understand this specialization of the statistical characteristics, because it is one of the most powerful features of the algorithm: by summarizing in a topology the statistical space contained in the original dataset, the SOM provides a visualization that makes intuitive the detection of particular patterns that would otherwise remain hidden.

A SOM network can be used in many ways. Two of the most popular ones include the component planes and the visualization of the best matching units (BMUs ). As mentioned before, each hexagon represents a vector of as many dimensions as the original dataset and, once trained, these vectors incorporate its statistical properties as well. One way to visualize the output of a SOM is to map onto the network of hexagons the values of each of these dimensions (component planes) to analyze how different variables are distributed and, particularly, whether there are any patterns or resemblance between variables. For example, a similar distribution for two variables would indicate a positive correlation between them. Another possibility the SOM offers is to link the network of hexagons to the original observations. This is done by exploiting the concept of best matching unit (BMU): for each observation in the original dataset, its BMU is defined as the most similar hexagon in the SOM as measured by (Euclidean) distance to the vector assigned to it. The BMUs represent the XY coordinates of the original observations in the new map created. This means we can now map each of those observations onto the statistical map we have created and analyze their distribution. Because of the properties of the SOM, statistical similarity is translated into spatial distance so that observations that are very much alike will tend to be located close to each other while very different ones will be distant in the network. SOMs have indeed gained much interest in recent social science research.

After the presentation of the Super-DEA model (in Section 4) and the SOM approach (in Section 5), we will now present the results for our Moroccan diaspora entrepreneurs in Section 6 and 7 , respectively.

\section{Results of the Super-DEA Model for Migrant Entrepreneurs}

In this section, we will present the efficiency evaluation results from the DEA and SuperDEA analyses applied to detailed data on 5 inputs (HC, SC, EC, CC\&KC and FC) and the 2 outputs (FBP1\&2 and NF-BP3) in Table 1 of 24 Moroccan entrepreneurs in order to assess their 
quantitative performance by investigating more carefully the ratio between multi-attribute outputs and multi-attribute inputs. The DEA analysis offers a measure of the relative efficiency (and inefficient) of each DMU considered, using the highest performing agent as a benchmark. The efficiency evaluation results for the selected migrant entrepreneurs based on the application of a standard CCR-I model are given in Figure 3.

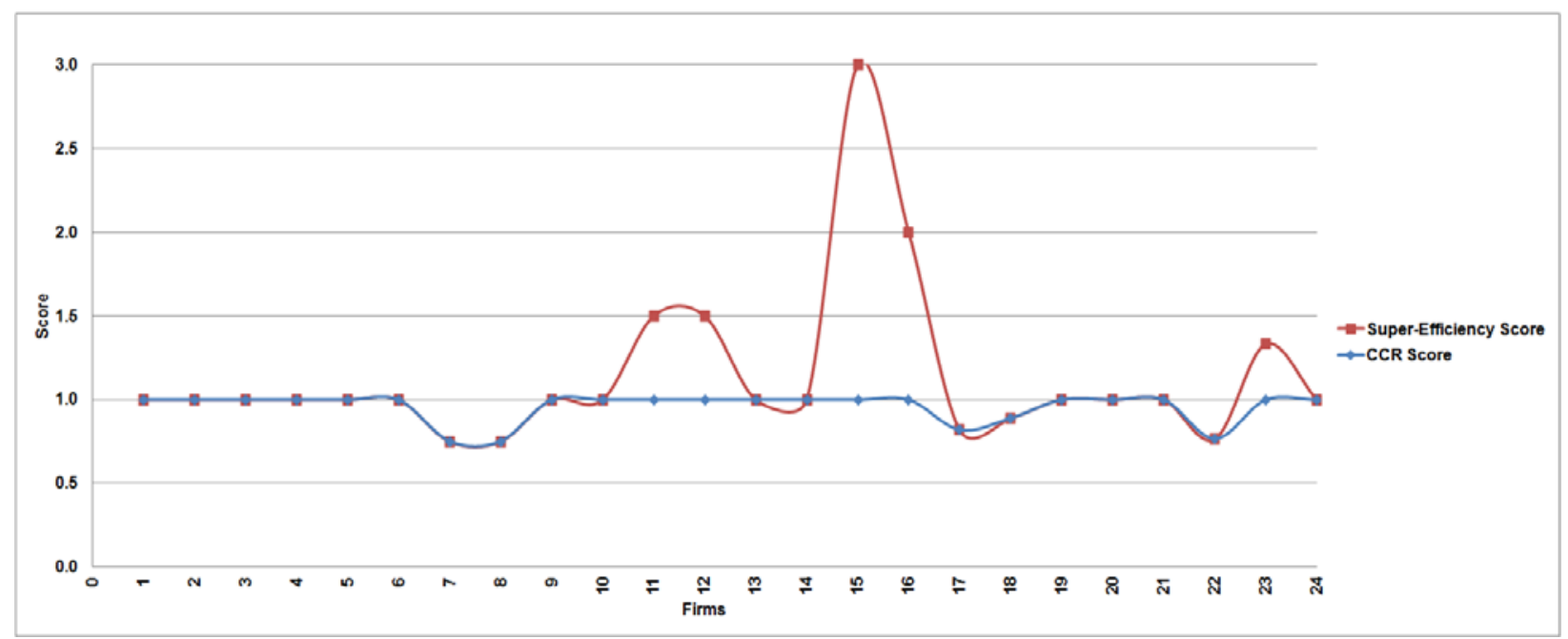

Figure 3. Efficiency score based on the CCR model and the Super-DEA model

Figure 3 presents the empirical results for the DEA approach applied to the sample of Moroccan firms, by using both the CCR-1 DEA algorithm and the Super-DEA algorithm. Using a conventional DEA analysis (with a maximum score of 1), i.e., the most efficient migrant firms producing a high performance (output) with a minimum use of inputs) to assess scores for the performance of each individual migrant firm - we can conclude from Figure 3 that the overall efficiency level of migrant firms shows a rather stable pattern. There is apparently relatively little variation in the efficiency performance of these firms according to the CCR-I model. Clearly, the inefficient migrant firms (i.e., firms 7, 8, 17, 18 and 22) have a score below the efficiency frontier, with a gradually declining standard DEA score far below the maximum efficiency score of 1 . Now the intriguing question is: can we identify from this set of Moroccan entrepreneurs a firm that may be coined the 'Business Champion'? To answer this question, we present the Super-Efficiency results (based on a adjusted ranking of efficient DMUs) through the use of an adjusted DEA analysis, in which we are also able to further discriminate between the class of efficient DMUs - i.e. the most efficient migrant firms - in our search of the 'Business Champion'. Consistent with the ranking of the Super-DEA values, 5 of the 24 migrant firms were identified with a high Super-Efficiency score (i.e., firms 11, 12, 15, 16 and 23), giving a stability score ranging from 1,333 to 3,000 . This indicates that these 5 firms are most robustly efficient. It is noteworthy that in our analysis "firm 15" is the 'winner' in this competitive identification of the most efficient 'Business Champion' based on the Super-DEA model. This is an unambiguous result that originates from the advantages of the use of the Super-DEA principle. The next in ranking appears to be firm 16, followed by firm 11, 12 and 23. 


\section{Results of SOM of Migrant Entrepreneurs}

\subsection{Introductory remarks}

This section presents the results from applying a SOM approach in a series of steps to understand better the structure and a short-term evaluation of the information contained in our ethnic entrepreneurs' dataset described in Section 3. Three different SOMs have been run based on three different partitions of the dataset:

1. The input variables $H C, S C, C C \& K C, E C$ and $F C$

2. The output variables FBP1\&2 and NF-BP3

3. All eight variables together, the so-called 'global score'.

The main objective of this mapping is to identify possible interesting profiles and patterns in the performance that emerge among the observations of migration businesses. Thus, first we will show the main network with the mapping of a spatial representation of these firms' performance to gain an adequate understanding of its composition, followed by maps with the location and the efficiency scores. This map will also display an additional layer of information by using different colours to mark the location of each firm and where a set of efficiency scores will be divided in five categories by the natural breaks methodology and assigned by a colour in the gradient from light to dark blue. Finally, the component planes are also presented in a gradient of five quantiles from light to dark blue to present the distribution of values of each variable across the SOM.

\subsection{Location factors and spatial distribution of migrant entrepreneurs}

The main tool we use to accomplish our purpose is the SOM network whose results are displayed in Figure 4. Onto this map, it is possible to locate each of the input the firms used in our analysis, according to their values for each variable considered. Figure 4 shows a statistical map with the distribution of the migrant entrepreneurs, where one group of firms may be very similar in terms of performance and share similar characteristics, while others are as different as the sample gets. An interesting question to ask now is whether there is any systematic pattern across the configuration of migrant firms within the statistical map displayed in Figure 4.

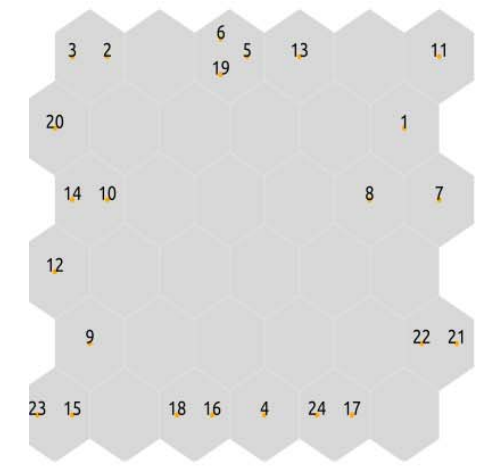

(a) SOM with input variables

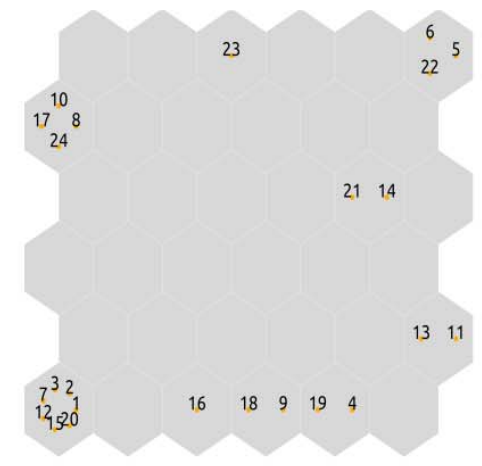

(b) SOM with output variables

Figure 4. Distribution of migrant firms across statistical space

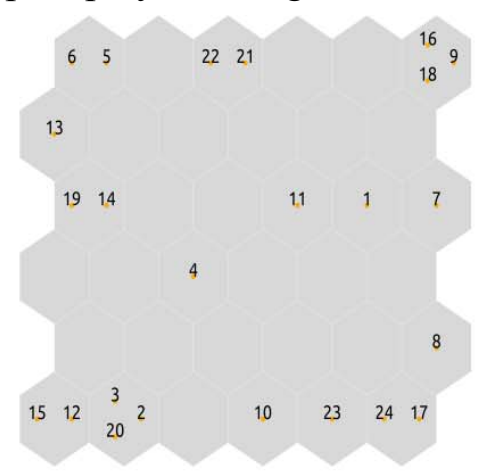

(c) SOM with input and output variables 
Figure 4 represents a topological virtual map obtained from a SOM network trained by using all three different partitions of the dataset explained in Section 3. Comparing the general layouts of the observed migrant businesses in each SOM reveals some interesting features. Figure 4(a) displays the position of the firms based on statistical associations, with a focus on topological similarities and dissimilarities in inputs among ethnic businesses. Figures $4(\mathrm{~b})$ and 4(c) offer SOM results based also on the output variables show two clear large clusters of migrant firms and a high global score degree of clustering, suggesting that these are similar groups of the observed migrant firms. Where Figure 4(a) shows that the distribution of migrant firms across the input and the global score SOMs is better spread across the networks suggesting larger degree of diversity between the observations as well as more particular and unique combinations of characteristics. Clearly, distance in Figure 4(a) implies dissimilarity: the more distant two observation points are, the more different characteristics they have, and vice versa. Some of observations such as firms 5 and 6 are very similar in all the SOM outputs, since they are located very close to each other, while others firms such as firms 14 and 19 show similar characteristics based on one SOM, the global score, though somehow different if the input or the output variables are considered separately.

\subsection{Highlights on the location and score patterns of migrant firms}

In our subsequent search for dispersion or location patterns of migrant firms, we first use a geographically-oriented variable 'geographical location in the Netherlands' of the firms concerned in order to analyse how this variable relates to their performance (in the spirit of the SOM approach presented in Section 7.1). Second, we also use now the variable we map onto the SOM as a quantitative index of performance derived from the Super-DEA. Its main idea is to find a numerical expression (based on a performance score ranging from 0 to 1 , with 1 being the highest score or the highest efficiency level) (see also Suzuki et al. 2010, 2011).

We now try to answer the question whether firms geographically located in the same Dutch city are mapped onto the same topological area of the SOM and thus have a similar performance. The maps in Figure 5(a), 5(b) and 5(c) display the distribution of the different four large Dutch cities $^{1}$ across the firm' performance space of the SOM where each category is assigned a colour and firms are coloured based on the category to which they belong in the variable of analysis. Next, Figures 5(b), 5(d) and 5(f) divide the firms into those with an efficiency score of 1 (dark blue) and those below that level (white).

In both cases, Figure 5 does not show clear patterns, neither in the geographical location scores nor in the efficiency scores. They both do not seem to display a high correlation with the inputs or the outputs. This is particularly true in the case of location. Despite a lack of general patterns, a few observed firms located in the Dutch cities at home can be found in the same specific domains of the SOM. For example, in Figures 5(a), 5(c) and 5(e) is Amsterdam in the

\footnotetext{
${ }^{1}$ Note: Colours in Figure 5 are associated with the following four large Dutch cities, in order of appearance in the legend: Amsterdam, The Hague, Rotterdam and Utrecht.
} 
global score (located along the bottom part) and in the output SOMs (along the left hand side) and The Hague (upper and bottom-right parts, respectively). However, Utrecht does not display a clear pattern at all probably due it has the largest number of observations which makes it harder from a cognitive perspective to visually detect patterns, even if they were to exist.

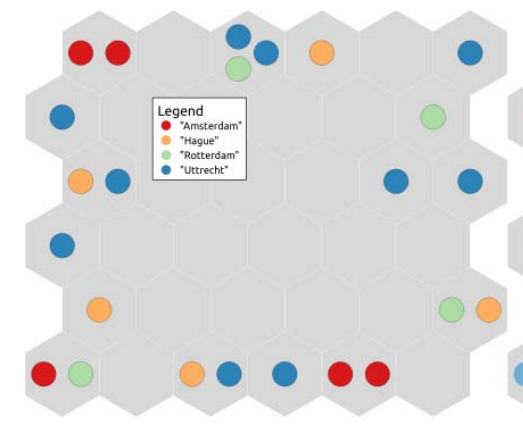

(a) Location (SOM using input variables)

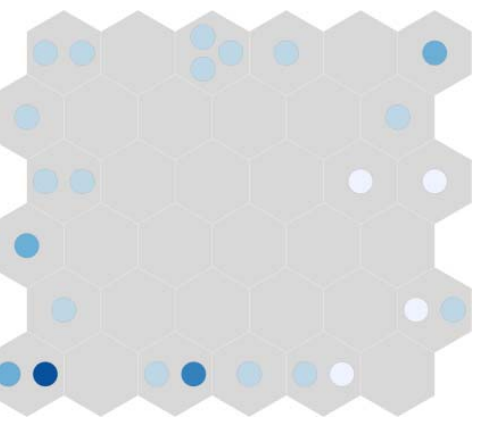

(b) Efficiency (SOM using input variables)

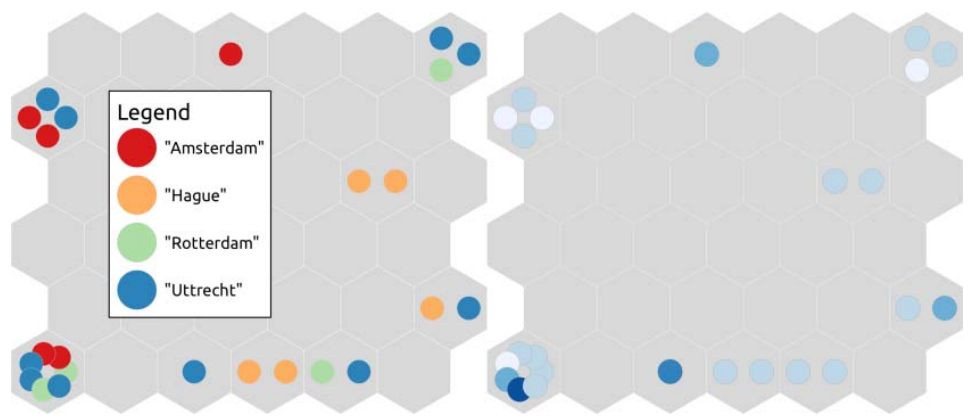

(c) Location (SOM using output variables)

(d) Efficiency (SOM using output variables)

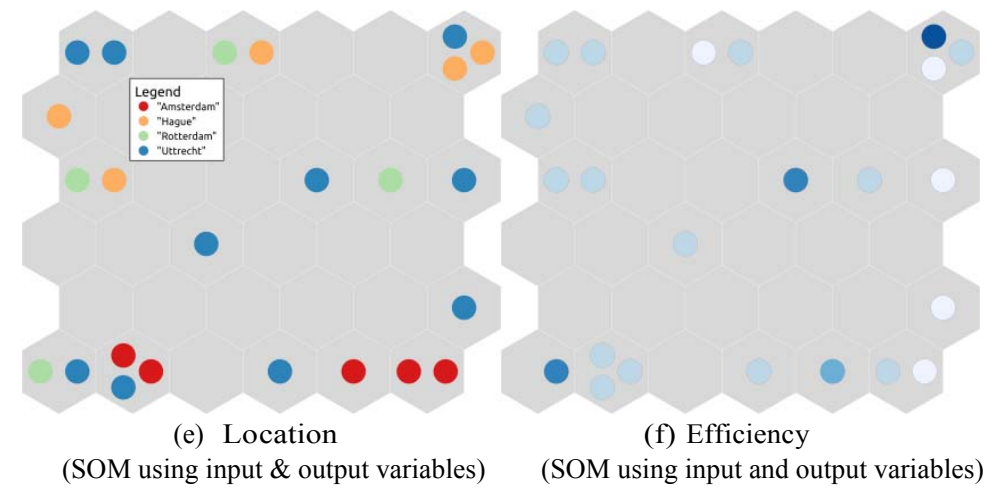

Figure 5. Distribution of Super- DEA scores and spatial variables across a performance-based SOM for migrant firms in Dutch cities

Figures 5(b), 5(d) and 5(f) present the map based on super-DEA in which the index divides the firms into those with the highest scores (dark blue), middle high scores (light blue) and those below that level (white). In the case of the super-efficient DEA, a few patterns can be distinguished in Figures 5(b) and 5(f). In Figure 5(b), the highest scores (dark blue) are either in the upper-right or bottom-left corners, middle high scores (light blue) are on the upperleft part, while the lowest scores (white) can be found on the bottom-right domain of the 
SOM. This pattern is also visually detected in Figure 5(f) where the highest scores are also found along the diagonal from the bottom-left to the top-right. The lowest scores can be found along the right edge, while the middle scores are more spread. In the case of Figure 5 (d) almost no pattern can detected.

This implies that the right edge and bottom-right regions of the map may be identified with low performance scores, while the upper-right or bottom- left regions display higher ones and, in this sense, are the winner areas of the SOM.

\subsection{A further analysis of the location patterns of migrant firms}

In order to better understand what the location patterns of migrant firms may mean, we need to know who is located where. We use an additional tool for that purpose: the component planes. The component planes are a representation of the distribution of the values of one of the dimensions used to run the SOM algorithm based on three different partitions of the dataset.

The planes are also very useful when compared with the location of the firms as well as with the efficiency scores, as well as to characterize different regions of the SOM and to link this information to the observations mapped into those areas.

Figure 6 displays, as a complement to figures 5(b), 5 (d) and 5(f) now the component planes for each of the specific performance variables in which the values are displayed on a gradient from white (lowest levels of that factor of performance) to dark blue (always implying a better performance) For instance, plane 4 in Figure 6(d), with SOM using input variables, displays the distribution of values of the variable 'Entrepreneurship Capital (EC). It is easy to see that the upper-right corner firms 23,15, 18 and 16, as we can also observe from figure 4(a), have very high scores on 'EC', but poor scores on 'Creative Capital \& Knowledge Capital $(C C \& K C)$ '. Similarly, the upper-left Firms $(3,2,20,6,19,5,13,11)$ perform poorly on this variable.

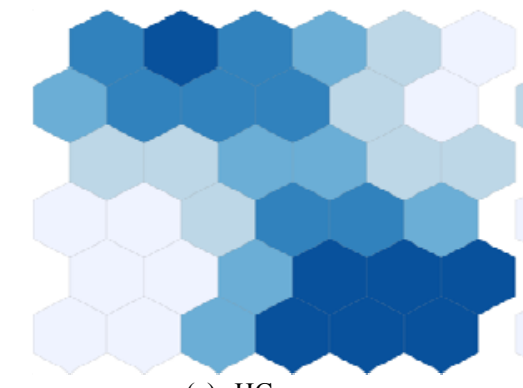

(a) $\mathrm{HC}$

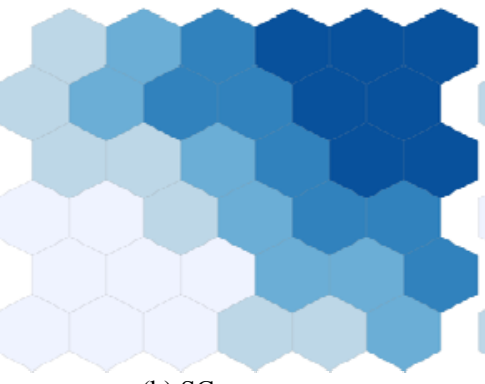

(b) $\mathrm{SC}$

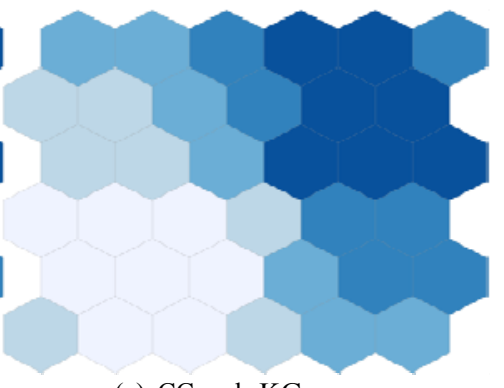

(c) $\mathrm{CC}$ and $\mathrm{KC}$

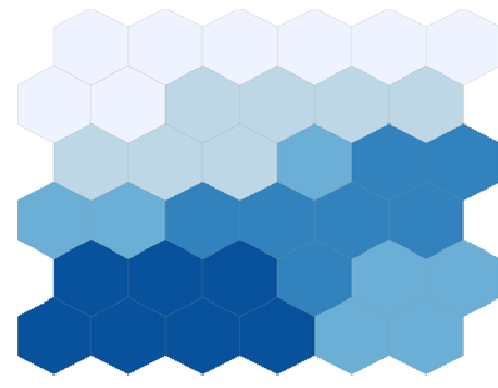

(d) EC

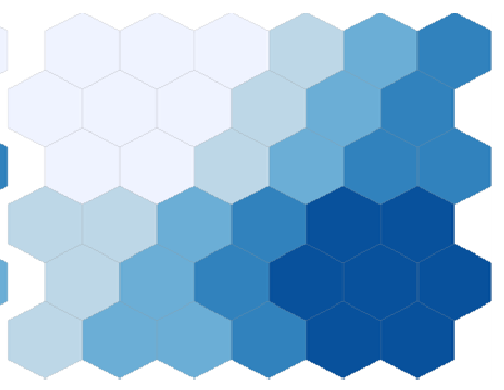

(e) FC

Figure 6 (a-e): SOM using input variables 


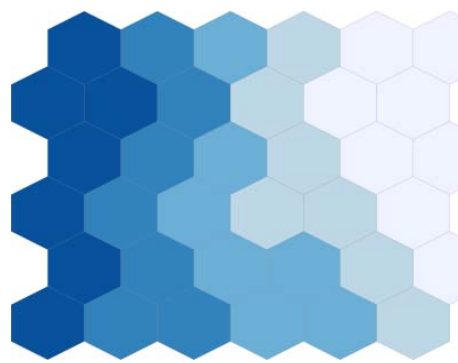

(f) Financial bp1 Output sales

Figure 6 (f-g): SOM using output variables

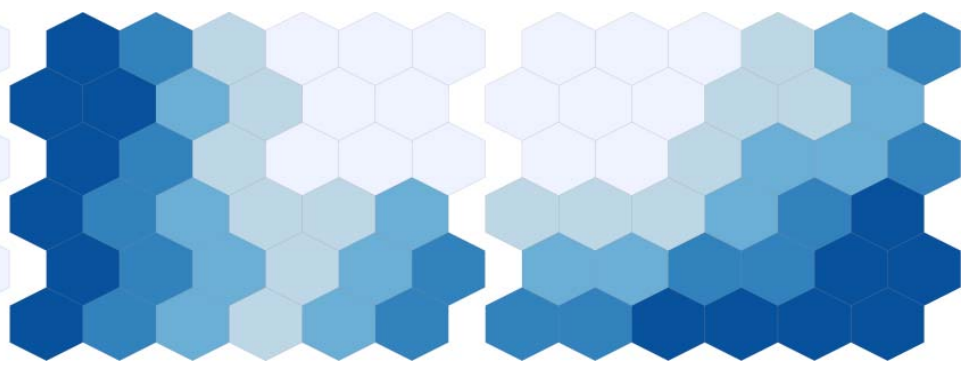

(g) Financial bp2 Output profit

(g) Non financial bp3 Output hoq

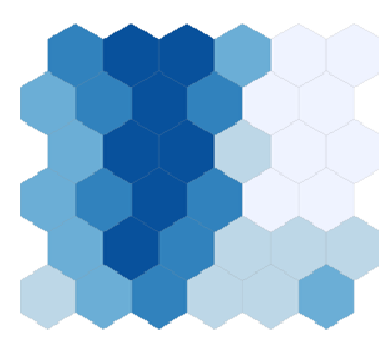

(i) $\mathrm{HC}$

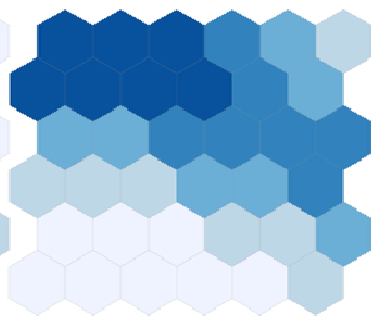

(j) SC

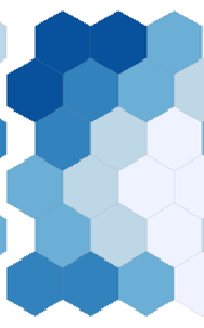

(k) $\mathrm{CC}$ and $\mathrm{KC}$

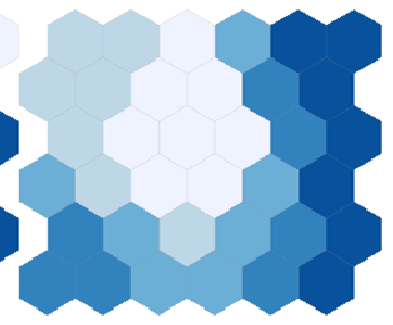

(1) EC

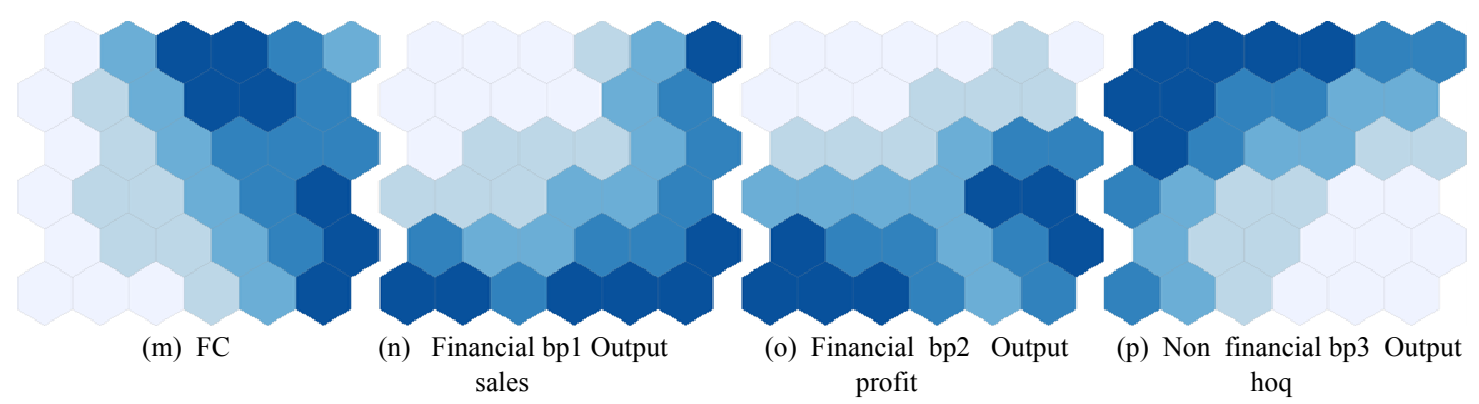

Figure 6 (i-p): SOM using input and output variables

\section{7. $\quad$ Retrospect and Prospect}

In the age of globalization, international mobility, which is closely related to migration, is a 'normal' socio-economic phenomenon. Migration has a clear socio-economic background in terms of income, wage, and job motives. Therefore, it cannot be ignored that the rising importance of migration worldwide is becoming an important part of our modern economic research. It is clearly a major development in our society, with many positive but also negative consequences involved.

Migration, with the exception of forced migration, has a clear socio-economic background. In particular, more favorable opportunities and network externalities are offered by large cities. Therefore, it comes as no surprise that large cities in the Netherlands have a relatively high share of migrants. Those cities are increasingly experiencing the same phenomenon as those in North America, namely a 'melting pot' of cultures and people. Cultural diversity represents a new challenge and provides opportunities for cities in host countries. International studies of various 
cities show that cultural diversity leads to favourable socio-economic conditions where they form complementary labour opportunities or niche-markets. To manage cultural diversity with the focus on the optimisation of a portfolio of socio-economic characteristics of cities requires the utmost in managerial courage and ability.

The research described in this article has focused on (i) answering the question whether enterprises with a given cultural or geographic origin have clear, interesting and novel patterns across migrant firms in terms of their performance in distinct Dutch cities, as well as (ii) the drivers that determine such outcomes. To answer this question we developed a conceptual and operational business performance model which comprises both individual-specific determinants (e.g. skills, age) and general moderator variables (e.g. geographic location). We have addressed in particular the next generation of skilled Moroccan entrepreneurs in Dutch cities.

Nowadays, the younger generation of entrepreneurs tends to be well-educated, and better integrated in the host community. Through their human capital, motivation and driving forces they have the ability to be involved in all areas of business activities. They are more open, looking for new opportunities beyond the traditional markets and products (economic expansion and business growth strategies). They aim to expand their market domain through break-out strategies, by offering high quality products and services to a broader group of clients and markets, outside their own indigenous ethnic group. They are attracted to new sectors, such as ICT, marketing, accountancy, global trade, real estate, consultancy, and leisure and recreation management agencies. Also, they want to expand into high-tech trade by engaging in trade with native entrepreneurs and other ethnic groups. Furthermore, factors such as capital and information sources show that the new generation entrepreneurs are quite independent of their family, friends, and social bonds. Thus, their social networks contribute to the independence of these entrepreneurs, while supporting their personal and human development in a broader societal context.

An important conclusion from this research is that the migrants' capacities and resources matter - and their ethnicity less so - in achieving business performance and success. Given this new view on the variety in motivations and background conditions of migrant entrepreneurs, it seems plausible to hypothesize that their economic performance will also show quite a diversity. This will have to be further tested in future research.

Our DEA analysis has aimed to shed new light on the efficiency and productivity of these migrant firms. The 'winners' in this competitive assessment of vital and highly efficient firms are thus characterized by a very high performance and are able to produce sustainable socioeconomic results. They are no doubt challenged to improve their competitive high performance, and to incorporate innovation and technology in overall developmental strategies so as to make their firms front-runners in their future development.

In our study, the multidimensional SOM visualization and the Super-DEA model have shown the relative differences in the performance of migrant entrepreneurs. The items from the four cities concerned are found in the same domain of the SOM. It is particularly interesting to uncover the main performance characteristics in the areas where each of these firms can be found. They may share high values on various particular variables, and thus in that regard they may be similar. However, they may differ in terms of other variables. Our results offer 
meaningful insights for decision support and planning for the strategic efficiency improvement of ethnic firms. Clearly, firms have always the possibility to increase their potential. This improvement potential differs for each firm, but our results offer operational guidelines on a case-by-case firm basis.

Our general conclusion is that their human capital and resources are of critical importance and that it is not their ethnicity that influences business performance and success. Recent new trends show that migrant (or ethnic) entrepreneurs have become a relatively new species in the urban space-economy. There is a clearly drastic transformation and re-positioning of conventional ethnic entrepreneurship. They become a source of new economic opportunities for regions and cities, engage in the introduction of new products and processes in the market (their diversity leads to new and innovative combinations, which in turn will attract new companies), and contribute to 'citymarketing' (e.g., the 'creative city') to attract visitors, talent, innovative companies and new residents. Their contribution to creative areas strengthens the urban social economy. It is noteworthy, that they provide a major challenge (as serious competitors) to established firms and prompt them to improve their product quality and service or to reduce prices. Thus, these migrant firms may generally be defined as 'Business Champions', inducing successful (break-through) innovative activities and a high socio-economic performance at a competitive edge, in particular, in such domains as advanced business and environmental facilities and creative, cultural and knowledge-intensive strategies. They are truly champions that act as spearheads of sustainable socio-economic growth in modern cities.

\section{Acknowledgment}

The authors wish to thank Soushi Suzuki for his great help in performing the Super-DEA experiment for the migrant firms.

\section{References}

Andersen, P., and N.C. Petersen, A Procedure for Ranking Efficient Units in Data Envelopment Analysis, Management Science, vol. 39, no. 10, 1993, pp. 1261-1264

Ansoff, I., Strategies for Diversification, Harvard Business Review, vol. 35, no. 5, 1957, pp. 113-124

Arribas-Bel, D., P. Nijkamp and H.Scholten, Multidimensional Urban Sprawl in Europe: A Self-Organizing Map Approach. Computers, Environment and Urban Systems, vol. 5, no. 4, 2011, pp. 263-275

Borjas, G.J., Heaven's Door, Princeton University Press, Princeton, NJ, 1999

Charnes, A., W.W. Cooper and E. Rhodes, Measuring the Efficiency of Decision Making Units, European Journal of Operational Research, vol. 2, 1978, pp. 429-444

Christensen, P., P. Gandhi and J. McCluskey, The Benefits and Costs of Immigration, Moving Forward: The Immigration Debate and Chicago's Experience, The Chicago Council on Global Affairs, Chicago, Ill., 2011, pp. 14-32

Engelen, E., Breaking-in and Breaking-out; a Weberian Approach to Entrepreneurial Opportunities, Journal of Ethnic and Migration Studies, vol. 27, no. 2, 2001, pp. 203-223.

Florida, F., The Rise of the Creative Class, Basic Books, New York, 2002.

Fukuyama, F., Trust: The Social Virtues and the Creation of Prosperity, Free Press, New York, 1996

Gang, J., B. Higgins, R.L. Rodriguez, A. Simpkins and M.M. Zaikos, From Melting Pot to Mosaic, Moving Forward: The Immigration Debate and Chicago's Experience, The Chicago Council on Global Affairs, Chicago, Ill, 2011, pp. 45-60

Jacobs, J., The Death and Life of Great American Cities, Random House, New York, 1961 
Kloosterman, R., and J. Rath, Immigrant Entrepreneurs in Advanced Economies, Journal of Ethnic and Migration Studies, vol. 27, no. 2, 2001, 189-201

Kohonen, T., Self-organizing Maps, Springer, Berlin, 2001

Kourtit, K., and P. Nijkamp, Strategic Choice Analysis by Expert Panes for Migration Impact Assessment, International Journal of Business and Globalisation, vol. 7, no. 2, 2011a, pp. 166-194

Kourtit, K., and P. Nijkamp, Strangers on the Move: Ethnic Entrepreneurs as Urban Change Actors, European Research, 2011b (forthcoming).

Landry, C., The Creative City: A Toolkit for Urban Innovators, London, Earthscan, 2000.

Nijkamp, P., and J. Poot, Migration Impact Assessment: A State of the Art, Migration Impact Assessment: New Horizons (P. Nijkamp, J. Poot and M., Sahin, eds.), Edward Elgar, Cheltenham, 2012 (forthcoming)

Nijkamp, P., J. Poot and M. Sahin (eds.), Migration Impact Assessment: New Horizons, Edward Elgar, Cheltenham, 2012

Poot, J., B. Waldorf and L. van Wissen (eds.), Migration and Human Capital, Edward Elgar, Cheltenham, 2008

Putnam, R.D., Bowling Alone, Simon \& Schuster, New York, 2000

Sahin, M., Studies in Migrant Entrepreneurship in Dutch Cities, Ph. Dissertation, Dept. of Spatial Economics, VU University, Amsterdam, 2012

Scott, A.J., Creative Cities: Conceptual Issues and Policy Questions, Journal of Urban Affairs, 28, 2006, pp. 1-17.

Skupin, A. and R. Hagelman, Visualizing Demographic Trajectories with Self-Organizing Maps, GeoInformatica, vol. 9, no. 2, 2005, pp. 159-179.

Spielman, S. and J. Thill, Social Area Analysis, Data Mining, and GIS. Computers, Environment and Urban Systems, 2008, vol. 32, no. 2, pp. 110-122

Suzuki, S., P. Nijkamp and P. Rietveld, Regional Efficiency Improvement by Means of Data Envelopment Analysis through Euclidean Distance Minimization Including Fixed Input Factors: An Application to Tourist Regions in Italy, Papers in Regional Science, vol. 90, no. 1, 2011, pp. 67-89

Suzuki, S., P. Nijkamp, P. Rietveld and E. Pels, A Distance Friction Minimization Approach in Data Envelopment Analysis: A Comparative Study on Airport Efficiency, European Journal of Operational Research, vol. 207, 2010, pp. 1104-1115

World Bank, Global Economic Prospects: Economic Implications of Remittances and Migration, World Bank, Washington D.C., 2006

Yan, J. and J. Thill, Visual Data Mining in Spatial Interaction Analysis with Self-Organizing Maps, Environment and Planning B: Planning and Design, vol. 36, 2009, pp. 466-486. 